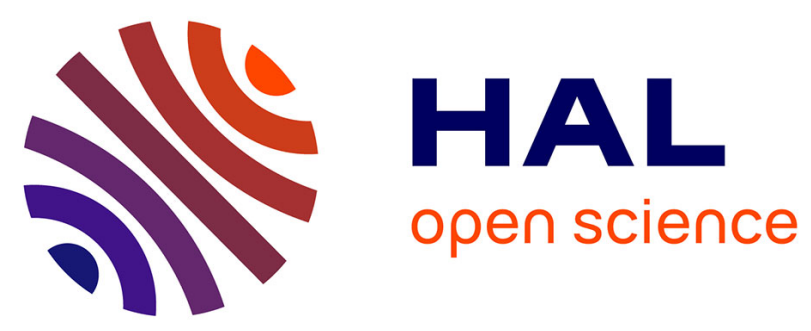

\title{
Learning to associate novel words with motor actions: Language-induced motor activity following short training
}

Raphael Fargier, Yves Paulignan, Véronique Boulenger, Padraic Monaghan, Anne Reboul, Tatjana A Nazir

\section{- To cite this version:}

Raphael Fargier, Yves Paulignan, Véronique Boulenger, Padraic Monaghan, Anne Reboul, et al.. Learning to associate novel words with motor actions: Language-induced motor activity following short training. Cortex, 2011, 48 (7), pp.CORTEX 692. 10.1016/j.cortex.2011.07.003 . hal-00613599

\section{HAL Id: hal-00613599 https://hal.science/hal-00613599}

Submitted on 5 Aug 2011

HAL is a multi-disciplinary open access archive for the deposit and dissemination of scientific research documents, whether they are published or not. The documents may come from teaching and research institutions in France or abroad, or from public or private research centers.
L'archive ouverte pluridisciplinaire HAL, est destinée au dépôt et à la diffusion de documents scientifiques de niveau recherche, publiés ou non, émanant des établissements d'enseignement et de recherche français ou étrangers, des laboratoires publics ou privés. 
Learning to associate novel words with motor actions: Language-induced motor activity following short training

Raphä̈l Fargier', Yves Paulignan', Véronique Boulenger ${ }^{2}$, Padraic Monaghan $^{3}$, Anne Reboul $^{1}$, and Tatjana A. Nazir ${ }^{1}$

1. L2C2-Institut des Sciences Cognitives, UMR 5230 CNRS/UCBL, 67 Bd Pinel, Université Claude Bernard Lyon1, 69675 Bron Cedex, France

2. Laboratoire Dynamique du Langage, UMR 5596 CNRS - Universite' de Lyon, Institut des Sciences de l'Homme, 14 Avenue Berthelot, 69363 Lyon Cedex 07, France

3. Department of Psychology, Lancaster University, Fylde College, Lancaster LA1 4YF, United Kingdom

Correspondence to:

Raphaël Fargier

L2C2-Language, Brain and Cognition Laboratory

Institute of Cognitive Science

67 Bd Pinel

69675 Bron, France

Email: raphael.fargier@isc.cnrs.fr

Phone number: $+33(0) 437911251$ 


\section{Abstract}

Action words referring to face, arm or leg actions activate areas along the motor strip that also control the planning and execution of the actions specified by the words. This EEG study aimed to test the learning profile of this language-induced motor activity. Participants were trained to associate novel verbal stimuli to videos of object-oriented hand and arm movements or animated visual images on two consecutive days. Each training session was preceded and followed by a test-session with isolated videos and verbal stimuli.

We measured motor-related brain activity (reflected by a desynchronization in the $\mu$ frequency bands; 8-12 Hz range) localized at centro-parietal and fronto-central electrodes. We compared activity from viewing the videos to activity resulting from processing the language stimuli only. At centro-parietal electrodes, stable action-related $\mu$ suppression was observed during viewing of videos in each testsession of the two days. For processing of verbal stimuli associated with motor actions, a similar pattern of activity was evident only in the second test-session of day 1. Over the fronto-central regions, $\mu$ suppression was observed in the second test-session of day 2 for the videos and in the second testsession of day 1 for the verbal stimuli.

Whereas the centro-parietal $\mu$ suppression can be attributed to motor events actually experienced during training, the fronto-central $\mu$ suppression seems to serve as a convergence zone that mediates underspecified motor information. Consequently, sensory-motor reactivations through which concepts are comprehended seem to differ from those implicated in their acquisition. 


\section{Introduction}

In their seminal work, Hauk et al. (2004) demonstrated that words referring to face, arm or leg actions differentially activated areas along the motor strip that are adjacent to or overlapping with areas activated by the movement described by the words. This result was taken to suggest that the referential meaning of action words has a correlate in the somatotopic activation of motor and premotor cortex. A number of imaging studies have since reported related findings (Aziz-Zadeh et al., 2006; Boulenger et al., 2009; Kemmerer et al., 2008; Tettamanti et al., 2005) but disagreements about how to interpret these observations have also accumulated. Essentially, the debate focuses on the question as to whether language-induced cortical motor activity is a source or, rather, a consequence of language understanding (see Mahon and Caramazza, 2008 for a stimulating discussion). While advocates of "embodied theories" of semantics interpret the results as evidence that we use our motor system to understand language about actions (e.g., Allport, 1985; Fischer and Zwaan, 2008; Gallese and Lakoff, 2005; Martin et al., 1996; Pulvermüller, 1999), opponents of this view suggest that language-induced motor activity is an "after-effect" of language understanding that follows computations of abstract conceptual representations of action words performed elsewhere in the brain (Damasio, 1989; Mahon and Caramazza, 2008; see also Patterson et al., 2007; Simmons and Barsalou, 2003 for related proposals). Given the difficulty of isolating the functional role of motor activity during language processing, this debate seems as yet irresolvable. However, studies that probe the trajectory of learning of motor-language associations may provide insight into the causal role of motor activity for language processing.

The arbitrary relationship between the phonological forms of words and their meaning necessarily entails that cortical motor activity observed during the processing of verbal action description is the result of learning. In fact, according to an idea first put forward by Pulvermüller (1999, 2005), links between brain regions involved in language processing and brain regions involved in action planning/execution could develop through Hebbian associative learning. Since "action words" (mostly verbs) are often acquired and experienced in the context of execution of the depicted actions (Goldfield, 2000), and given Hebb's postulate that synchronous activity of neurons leads to the formation of neuronal assemblies (Hebb, 1949), Pulvermüller suggested that neural networks including perisylvian language areas and motor areas emerge with experience. By means of these shared circuits, perceiving an action word will then automatically trigger activity in motor regions of the brain (see also Del Giudice et al., 2008, and Keysers \& Perret, 2004, for similar ideas regarding potential links between action execution and observation systems).

The assumption that association learning can rapidly generate such shared neural circuits is supported by studies showing that the selectivity of the brain's motor response to a given perceptual stimulus changes with learning. In a study by Catmur et al. (2008), a group of participants were trained over 
three consecutive days to perform an action with the hand while observing a similar hand action. the foot. After training, motor areas that showed greater responses to the observation of hand actions in the first group, responded more strongly to observation of foot actions in the second group (see also Catmur et al., 2007). Relatedly, Lahav et al. (2007) showed that shared circuits between auditory processes involved in music perception and motor processes involved in piano playing can emerge rapidly with training. In this study, non-musicians were trained to play a piano piece over a five day training period. When playing the piano, auditory feedback is naturally induced by each of the player's movements leading to a tight coupling between perception and action. Following training, simply listening to the newly acquired piece of music triggered activity in cortical motor regions. McNamara et al. (2008) reported similar results for sound-gesture associations. Finally, in a complex learning experiment, Kiefer et al. (2007) taught participants over a period of three weeks to categorize a large number of novel objects into different object categories by either pantomiming a functional action that could be associated with the object or by simply pointing to the objects. Following training, presentation of the objects triggered activity in visuo-motor and frontal motor regions when training involved pantomiming but not when it involved pointing (see also Weisberg et al., 2007 for similar results for novel tool use).

All these learning experiments clearly demonstrate that cortical motor responses to perceptual stimuli can rapidly change with experience. Consequently, it should not be surprising to find similar effects when we learn to associate novel word-forms with self-performed motor actions. Indeed, Revill et al. (2008), using fMRI, trained participants to associate novel verbal stimuli with motion changes of objects and demonstrated that following training, participants showed greater language-induced activation in cortical regions that had been linked to the processing of motion and to the processing of motion-related real words (e.g., left MT/V5 and its anterior part; Kable et al., 2002, 2005; Martin et al. 1995). However, the low temporal resolution of fMRI means it is unclear exactly when this languageinduced motor activity becomes evident and how it evolves during training. To align the findings of Hauk et al. (2004) with research on the acquisition of word-referent relations, we therefore propose to monitor the temporal dynamics of learning word-action associations in adult participants, from the beginning of training to the point when associations are well established in behavior. Following the prediction by Pulvermüller (1999) and in line with previous learning experiments, we assume that associating novel verbal stimuli with a novel hand/arm movement (but not with a novel animated visual image) will lead to co-activation of perisylvian language regions and motor regions of the brain. Subsequent to training, the verbal stimuli alone should thus trigger activity in motor regions.

To study the dynamics of word-action associations, we analyzed oscillations of EEG (electroencephalogram) in the $8-12 \mathrm{~Hz}$ frequency range (i.e., " $\mu$ rhythms"; Gastaut, 1952) while participants listened to initially novel verbal stimuli, at four periods during training over two 
consecutive days. $\mu$ rhythms are typically present at rest but are suppressed, for instance, when

\footnotetext{
${ }^{1}$ Backward speech was used to determine effects of stimulus familiarity. However, for these stimuli associations were not fully acquired even at the end of Day 2. Therefore, data for these stimuli are difficult to interpret and were not further considered.
} the EEG caused by an increase of neural activity in somato-sensory cortex (Hari et al., 1997). In line with fMRI studies that indicated neural motor activity while listening to action sounds or observing actions (Buccino et al., 2004; Kilner et al., 2009; Rizzolatti et al., 1996), $\mu$ suppression has also been observed when participants hear the sound of actions (Caetano et al., 2007) or when they observe a movement performed by others (see Pineda, 2008, for a review). In the present study we therefore first identified EEG electrodes for which $\mu$ suppression was evident during movement observation, then we subsequently focused on these "electrodes of interest" for the analysis of $\mu$ suppression during processing of newly acquired action words.

\section{Materials and method}

\subsection{Participants}

Sixteen right-handed (scores $0.79 \pm 0.2$; Oldfield, 1971) French native volunteers participated in the study ( 9 females; mean age $24.2 \pm 4$ years). None of the participants had a history of psychiatric or neurological disorders and all had normal or corrected-to-normal vision. Participants gave written consent to partake in the study in accordance to the Helsinki declaration (1968). They were paid for their participation.

\subsection{Stimuli}

The stimuli consisted of 20 different video clips (presented on a computer screen $80 \mathrm{~cm}$ from the participants) and 20 novel verbal stimuli. Half of the clips consisted in reaching-and-grasping movements towards a horizontally or vertically oriented cylinder. The object-directed movement was performed with the right hand. Each movement started from a rest position (the hand on a table in front of the actor's torso) and ended with the grasping of the object. Movements differed in the way the hand moved towards the object (e.g. a zigzag movement). The other half of the clips consisted of animated artificial images, which differed in shapes, colors and animations (see Figure 1). Ten pseudo-words and their temporally reversed counterparts (backward speech ${ }^{1}$ ) served as verbal stimuli. Pseudo-words were bisyllabic and were obtained by changing one or two letters from frequent French words (i.e. they respected the phonotactic rules of French). Average length of the verbal stimuli was $665 \mathrm{msec}( \pm 123)$. Average length of video clips was $4600 \mathrm{msec}( \pm 1170)$ for movement-clips and $3900 \mathrm{msec}( \pm 1290)$ for image-clips. Verbal stimuli were presented binaurally through loudspeakers. 
Figure 1 about here.

\subsection{Procedure}

The experiment was conducted over two consecutive days. Each day included three sessions. Day 1 started with a test-session in which participants were instructed to listen attentively to the verbal stimuli and watch the video clips one by one. This first test-session was followed by a training-session in which participants learned to associate verbal stimuli and video clips. The training session was followed by a second test-session, which was identical to the first. Finally, a behavioral test assessed the effectiveness of learning. Day 2 started with a test-session followed by a training-session, a further test-session and the behavioral test. The exact procedure of each part of the experiment is described below. Note that EEG was recorded throughout all sessions. However, during training EEG recordings resulted in noisy signals and were thus not analyzed.

\subsubsection{Day 1}

2.3.1.1. First test session. During the test-sessions the 20 verbal stimuli (pseudo-words and backward speech) and the 20 video clips (image or reaching/grasping movement) were presented in isolation in a pseudo-random order. For each trial, participants were requested to fixate on a crosshair at the center of the computer screen, which lasted for $500 \mathrm{msec}$, and to pay attention to the auditory or visual stimuli presented subsequently. At the end of each trial a grey screen appeared for $1 \mathrm{sec}$, allowing participants to blink. Each stimulus was presented 5 times for a total of 200 trials.

2.3.1.2. Training session. Each training trial started with a fixation cross, presented for $500 \mathrm{msec}$ at the centre of the screen. The cross was followed by the presentation of a video clip (image or reaching/grasping movement). Participants were instructed to watch the video. A white screen of 500 msec marked the end of the clip. The same clip was then displayed again together with the verbal stimulus, which was presented shortly after the onset of the clip. When the clip depicted a movement (movement condition) the onset of the verbal stimulus coincided with the beginning of the movement and participants were requested to imitate the movement while listening to the verbal stimulus. When the clip showed an animated image, participants simply observed the image again while listening to the verbal stimulus (image condition). Participants were explicitly instructed to associate the verbal stimulus with the movement or the image depicted in the clip. To ensure that participants had finished imitating the movement before the beginning of the next trial, the experimenter triggered the trials manually. Each verbal stimulus/video clip pairing was displayed 15 times and the 300 trials in total were presented in pseudo-random order. A break was proposed to the participants after every 100 trials. The coupling of a given verbal stimulus with a given video clip was counter-balanced between 
participants such that the same verbal stimulus was associated with a movement for one participant and with an image for another.

\subsubsection{Second test session. Identical to 2.3.1.1.}

2.3.1.4. Behavioral task. In order to quantify learning performance, a behavioral test was performed as the final session on each day. For this, the 20 verbal stimuli were presented one by one and participants were requested to indicate if the stimulus was associated with an image or a movement in the previous training session. For verbal stimuli coupled with a movement, participants were asked to reproduce the movement. For verbal stimuli coupled with an image, they were asked to describe shapes, colors and animations.

\subsubsection{Day 2}

Day 2 started with a test-session, followed by a training-session, another test-session and the behavioral test. Except for a reduction in the number of repetitions in the training session (10 instead of 15) all experimental procedures were identical to those described for day 1.

\subsection{Data acquisition}

EEG data were recorded using BrainAmp amplifiers (Brain Vision recorder software, Brain Products $\mathrm{GmbH}$, Munich, Germany). EEG was recorded from 32 scalp sites using the international 10-20 system (American Encephalographic Society, 1994), with a forehead ground. Impedance was $10 \mathrm{~K} \Omega$ or less at the start of the recording. All scalp sites were referenced to the left mastoid. Horizontal and vertical eye movements were monitored using electro-oculograms (EOG) with a bipolar recording from electrodes placed on the outer canthi of the left eye. ERPs were sampled at $500 \mathrm{~Hz}$.

\subsection{Data analysis}

EEG activity was analyzed using BrainVision Analyzer 2.0 software (Brain Vision analyzer software, Brain Products $\mathrm{GmbH}$, Munich, Germany). First, a notch filter ( $>50 \mathrm{~Hz})$ was applied. The EEG was then re-referenced to an average reference (Bertrand et al., 1985) excluding both hEOG and vEOG. A manual inspection of the raw data was performed before the application of an ocular correction ICA (512 ICA steps; convergence bound of $1.10^{-7}$ ). Data were grouped according to the six conditions (movement video-clips; image video-clips; pseudo-words associated with an image; pseudo-words associated with a movement; backward speech associated with an image; backward speech associated with a movement) and epoched from $-500 \mathrm{msec}$ to $1500 \mathrm{msec}$ relative to stimulus onset. Trials were baseline corrected (200 msec pre-stimulus baseline). Wavelet transformation in the 1-30 Hz domain (frequency steps of 20) was computed for each trial by convolving a Morlet wavelet with the signal with a width of 7 cycles (van Elk et al., 2010). Trials were averaged for each condition. Grandaverages were then calculated over all participants. 


\subsection{Statistical analysis}

To test for statistical significance, the average amplitude of $\mu$ oscillations (8-12 $\mathrm{Hz}$ range) was computed for each condition and test-session over successive segments of $50 \mathrm{msec}$, starting from 0 msec to $1000 \mathrm{msec}$ after stimulus onset (van Elk et al., 2010). Repeated-measures analyses of variance (ANOVAs) that contrasted $\mu$ oscillations in the "movement condition" to the "image condition" were then performed for all time-windows. Main factors included: day (first and second day of the experiment), test-session (first and second test-session of the day), condition (movement and image) and electrode (see Results section for the identification of "electrodes of interest"). Note that to reduce false positives, several consecutive intervals should show significant effects $(p<.05)$ (see van Elk et al. 2010). Post-hoc (LSD-Fisher) analyses for test-sessions were therefore performed only when three or more consecutive time-bins showed a significant effect of the factor test-session and only within the time interval identified in the main analysis.

\section{Results}

\subsection{Behavioral data}

Participants had acquired all associations between verbal stimuli and depicted movements or images at the end of Day 1 and remained at ceiling at Day 2.

\subsection{EEG data}

\subsubsection{Videos: Electrodes of interest}

The onset of all videos triggered $\mu$ suppression over large parts of the head. To identify "electrodes of interest", we thus contrasted the topography of $\mu$ oscillations to videos that depicted the reaching-andgrasping movements to those that depicted the animated artificial images. Figure 2 shows spatial cartographies that present the difference in $\mu$ oscillations (in the $8-12 \mathrm{~Hz}$ frequency range) between the two conditions (movement-condition minus image-condition) within a time window of 250-1000 msec after video onset. Data are plotted separately for the four test-sessions. In line with previous studies showing reduced $\mu$ activity during preparation or observation of finger/hand movements over centroparietal sites contra-lateral to the performing hand (e.g. Pfurtscheller et al., 1997; Babiloni et al. 2002), the contrast between movement-condition and image-conditions revealed a centro-parietal site over the left hemisphere at which stronger $\mu$ suppression was observed in the movement-condition. This pattern, which despite some variations could be restricted to electrodes CP1, CP3, P3 and Pz (CentroParietal cluster), was already present prior to training (i.e., during the first test-session of Day 1) and 
was observed in the remaining three test-sessions. Moreover, in agreement with data recently reported by van Elk et al. (2010), a cluster of electrodes over fronto-central regions showed stronger movement- than image-related $\mu$ suppression, especially at the second test-session of each day. This second region of interest involved electrodes F3, F4, Fz, FC1, FC3, FC2 and FC4 (Fronto-Central cluster).

Figure 2 about here

Figure 3 illustrates time-frequency analyses (pooled over the previously identified electrodes for the left centro-parietal region (A) and for the fronto-central region (B)), for the first and second test session of each day. Data are plotted separately for the movement-condition (upper row) and the image condition (middle row). The third row shows the difference between the two conditions (movement-condition minus image-condition). Figure $3 \mathrm{C}$ plots $\mu$ activity $(8-12 \mathrm{~Hz}$ only) for each of the involved electrodes (black curves represent data for the movement-condition, red curves for the image-condition). These figures show that in the movement-condition as well as in the imagecondition $\mu$ suppression started to become evident between 200-400 msec after video onset. However, at centro-parietal electrodes, a tendency for stronger $\mu$ suppression during viewing of videos depicting the reaching-and-grasping movements was evident in all test-sessions. The ANOVA for this cluster of electrodes revealed no main effects, but a significant interaction between factors electrode $\mathrm{x}$ condition was observed for seven consecutive time-bins (from $450-850$ msec post-stimulus onset; all $p<.05$ ). The interaction between electrode $\mathrm{x}$ condition was due to variations of the effects at the different electrodes; see Suppl. material). This analysis thus indicates that at centro-parietal electrodes the effect of condition was present prior to training and was maintained throughout all test-sessions.

Figure 3 about here.

At the fronto-central site, display of videos had little impact on $\mu$ activity prior to training. However, $\mu$ suppression intensified in the test-session that followed training, with a tendency for stronger $\mu$ suppression in the movement-condition. This pattern was observed on both days. The ANOVA confirmed the effect of test-session in sixteen consecutive time-bins from 200-1000 msec poststimulus onset (all $\mathrm{p}<.05)$. A significant interaction between electrode $x$ condition was also seen during five consecutive time-bins from $600-850 \mathrm{msec}$ after stimulus onset (all $\mathrm{p}<.05$ ), confirming that $\mu$ suppression was stronger during viewing of videos depicting motor actions. Finally, a significant day $\mathrm{x}$ test-session $\mathrm{x}$ condition $\mathrm{x}$ electrode interaction in fourteen consecutive time bins from 300-1000 msec post-stimulus onset (all $\mathrm{p}<.05$ ) was found, suggesting that the effect of 
condition was stronger on Day 2 compared to Day 1. In separate ANOVAs for each of the two days no

Comparable to what was observed for the videos, modulation of $\mu$ activity at fronto-central electrodes was also mainly observed in the second test-session of each day.

However, whereas on Day 1 stimuli associated with a motor movement resulted in $\mu$ suppression, on Day 2 a tendency for an increase of $\mu$ activity was observed. The ANOVA indicated a significant main effect of electrode and a significant interaction between day x condition for three consecutive timebins (from 300-450 msec post stimulus onset; all $\mathrm{p}<.05$ ). The three-way interaction between day $\mathrm{x}$ condition $\mathrm{x}$ test-session, indicating a potential reversal of $\mu$ activity between the second test-session of Day 1 and Day 2, reached significance in one time bin only (from 300-350 msec after stimulus onset). A separate ANOVA for Day 1 indicated a significant interaction between test-session $\mathrm{x}$ condition in three time-bins (from 300-450 msec post stimulus onset; all $\mathrm{p}<.05$ ) and post-hoc analyses restricted the effect of condition to the second test-session (from 300-450 msec; all $\mathrm{p}<.05$ ). For Day 2 the ANOVA (or t-test) did not reveal any significant effects.

\section{Discussion}

By analyzing action-related $\mu$ oscillations in the EEG of adult participants, the present study monitored the temporal dynamics of learning word-action associations from the beginning of training to the point 
when associations are well established in behavior. In agreement with previous associative-learning experiments (e.g., Catmur et al., 2008; Kiefer et al., 2007; Lahav et al., 2007; McNamara et al., 2008; Revill et al., 2008; Weisberg et al., 2007), our behavioral data revealed that links between verbal stimuli and motor actions or images are rapidly established with training. At the end of training on Day 1, all participants correctly described the actions or images the novel verbal stimuli referred to. Performance stayed at ceiling on the following day. Moreover, during viewing of videos, strong and stable action-related $\mu$ suppression was seen over a centro-parietal region of the hemisphere contralateral to the performing arm during all four test-sessions. In line with results from previous studies (e.g., Pfurtscheller et al., 1997; Babiloni et al. 2002) this pattern of $\mu$ suppression thus seemed a good indicator of motor activity triggered by the observation/execution of actions depicted in the videos. Despite the fact that the topography of the identified region hinged on the specific contrast we performed (movement-condition minus image-condition), the pure association account by Pulvermüller (Pulvermüller, 1999; Gallese and Lakoff, 2005) predicted that after training, simply listening to verbal stimuli should trigger the pattern of brain activity that was seen during viewing of videos. Consistent with this prediction, once associations with verbal stimuli were established, a similar but weaker pattern of $\mu$ suppression was observed over the centro-parietal region during listening to verbal stimuli. This language-induced $\mu$ suppression was observed on Day 1 but not on Day 2.

Action-related $\mu$ suppression was also seen at electrodes over fronto-central regions of the two hemispheres. Yet, the pattern of $\mu$ oscillations at these electrodes was more complex and did not directly follow the prediction of the association account. Prior to training, activity at these electrodes was little affected by stimulus display. Moreover, action-related $\mu$ suppression for videos was not observed before the end of training on Day 2. Hence, it is unlikely that $\mu$ suppression at these electrodes was directly triggered by the observation/execution of actions depicted in the videos. This view is further supported by the fact that at fronto-central electrodes action-related $\mu$ suppression for verbal stimuli was seen prior to that of videos, that is, on Day 1. Then, on Day 2, training induced a tendency for an increase of action-related $\mu$ activity to verbal stimuli.

Hence, while language-induced motor activity seen at centro-parietal electrodes could be attributed to motor events actually experienced during training, the same does not hold for fronto-central electrodes. Rather, the observed pattern of training-dependent and action-related $\mu$ oscillations to videos and verbal stimuli could imply that these electrodes capture activity from regions that serve as “convergence zones” (Damasio, 1989) between language and motor structures. According to Damasio (1989), convergence zones are local brain areas in association cortices that do not by themselves contain refined representations. Instead, these zones receive/send signals from/to different modalities and enable correlated activity to occur in different regions of the brain. By way of these convergence zones - which evolve through learning - the brain can bind information represented in distinct regions 
into coherent events (e.g. sound and action), and can enact formulas for the reconstitution $\mu$ suppression for verbal stimuli as well as for videos emerged concurrently with the acquisition of word-action associations, suggests that activity at fronto-central electrodes reflects the development of such convergence zones.

The possibility that language-induced sensory and motor activity originates from convergence zones in higher-level association cortices has also been suggested by Kiefer et al. (2008). In their study, processing words denoting objects for which acoustic features are relevant (e.g., telephone) activated the auditory association cortex without activating the primary and secondary auditory cortex. According to Kiefer et al. (2008), conceptual processing only involves a partial reinstatement of brain activity during perceptual experience because the modality-specific experience of sensory conceptual features (e.g., experience a "ringing" sound when reading the word "telephone") would interfere with action planning processes. Other researchers have developed similar arguments. Willems et al. (2010), for instance, compared brain activity during reading action words and during explicit motor imagery of the actions described by the words. Their results revealed task-specific, non-overlapping and uncorrelated activity in parts of the premotor cortex. Based on this observation, the authors concluded that in contrast to motor imagery, language-induced motor activity might reflect underspecified rather than explicit motor representations. The underspecified nature of this representation would assure rapid and flexible accommodation of incoming information during on-line sentence processing. Thus, an explicit action plan for a word like "grasp" would differ depending on whether the word refers to grasping a baseball or grasping a needle. In support of this assumption, van Elk et al. (2010) showed that the strength of $\mu$ suppression over fronto-central regions varies when the sentential context offers more explicit information about the designated action: $\mu$ suppression observed while reading the verb "jumped" differed depending on whether the verb indicated an action performed by an animal ("the deer jumped over the stream") or by a human ("the athlete jumped over the fence").

Our results are not directly comparable to results obtained in studies that investigated languageinduced sensory-motor activity for well-known words because our study captured dynamic processes that occur during word-referent acquisition and prior to memory consolidation. However, the basic features of our findings are compatible with the proposals made by Kiefer and colleagues. Hence, early during training the pattern of the language-induced $\mu$ suppression observed at centro-parietal electrodes resembled the pattern that was observed during perceptual experience. This motor-activity, which could be interpreted as reinstatement of brain activity during perceptual experience, reduced as training progressed. Concurrently, action-related $\mu$ suppression emerged at electrodes that seemed to capture activity from convergence zones (c.f. over fronto-central regions). At these electrodes motor- 
activity was not present prior to training but developed for both type of stimuli (verbal stimuli and videos) with the acquisition of word-action associations ${ }^{2}$. Our training did not last long enough to capture a final, stable pattern. However, it is likely that over a more extensive training period, language-induced $\mu$ suppression would no longer be observed at centro-parietal electrodes, while at fronto-central electrodes solid patterns of action-related $\mu$ suppression would emerge for both verbal stimuli and videos.

\section{Conclusion}

According to embodied theories of semantics, cognitive processes are rooted in the body's interactions with the world. Within this theoretical frame, the present study probed the trajectory of learning motor-language associations to understand the functional role of neural motor activity observed during language processing (e.g. Hauk et al., 2004). By associating novel verbal stimuli with motor actions or animated images, our results demonstrated that brain responses to verbal stimuli change rapidly with training (see also Shtyrov et al., 2010 for related results) and form distinctions between the associated stimulus categories. Furthermore, verbal stimuli associated with motor actions trigger activity in motor regions of the brain. However, while this language-induced motor activity was initially very similar to motor activity observed during the perception of action, this pattern changed with training and suggested that overlapping activity between language and motor processes is confined to convergence zones between language and motor structures.

In line with suggestions made by other researchers (e.g., Kiefer et al., 2008; Thompson-Schill, 2003; van Elk et al., 2010; Willems et al., 2010), the present findings imply that language-induced motor activity observed for well-established words reflects underspecified rather than explicit motor representations. Such under-specification leads to a relative independence of the concepts in relation to its content that is identified in the similar but distinct well-described motor activity for action concepts or words. As a consequence, sensory-motor reactivations, through which concepts are comprehended, differ from those implicated in the acquisition of such concepts. Yet, even if these results might be interpreted as showing the first step of a gradual process of abstracting away from modality-specific representations (see Thompson-Schill, 2003), our findings nonetheless imply that, fundamentally, concepts are grounded in perception and action.

\footnotetext{
${ }^{2}$ Note that the delay in the emergence of action-related $\mu$ suppression for verbal stimuli and for videos could be related to our task. Given that our participants were requested to recall the action associated with the verbal stimuli and not the verbal stimuli associated with the action, action-related $\mu$ suppression in convergence zones might emerge first for verbal stimuli and then for videos.
} 


\section{References}

Allport A. Distributed memory, modular subsystems and dysphasia. In: Current perspectives in dysphasia (Newman SK, Epstein R, eds), Edinburgh: Churchill Livingstone, pp 207-244, 1985.

Aziz-Zadeh L, Wilson SM, Rizzolatti G, and Iacoboni M. Congruent embodied representations for visually presented actions and linguistic phrases describing actions. Curr.Biol., 16: 1818-1823, 2006.

Babiloni C, Babiloni F, Carducci F, Cincotti F, Cocozza G, Del PC, Moretti DV, and Rossini PM. Human cortical electroencephalography (EEG) rhythms during the observation of simple aimless movements: a high-resolution EEG study. Neuroimage., 17: 559-572, 2002.

Bertrand O, Perrin F, and Pernier J. A theoretical justification of the average reference in topographic evoked potential studies. Electroencephalogr.Clin.Neurophysiol., 62: 462-464, 1985.

Boulenger V, Hauk $\mathrm{O}$, and Pulvermuller F. Grasping ideas with the motor system: semantic somatotopy in idiom comprehension. Cereb.Cortex, 19: 1905-1914, 2009.

Buccino G, Lui F, Canessa N, Patteri I, Lagravinese G, Benuzzi F, Porro CA, and Rizzolatti G. Neural circuits involved in the recognition of actions performed by nonconspecifics: an FMRI study. J.Cogn Neurosci., 16: 114-126, 2004.

Caetano G, Jousmaki V, and Hari R. Actor's and observer's primary motor cortices stabilize similarly after seen or heard motor actions. Proc.Natl.Acad.Sci.U.S.A, 104: 9058-9062, 2007.

Catmur C, Gillmeister H, Bird G, Liepelt R, Brass M, and Heyes C. Through the looking glass: counter-mirror activation following incompatible sensorimotor learning. Eur.J.Neurosci., 28: 1208$1215,2008$.

Catmur C, Walsh V, and Heyes C. Sensorimotor learning configures the human mirror system. Curr.Biol., 17: 1527-1531, 2007.

Damasio AR. Time-locked multiregional retroactivation: a systems-level proposal for the neural substrates of recall and recognition. Cognition, 33(1-2):25-62, 1989.

Del GM, Manera V, and Keysers C. Programmed to learn? The ontogeny of mirror neurons. Dev.Sci., 12: 350-363, 2009.

Fischer MH and Zwaan RA. Embodied language: a review of the role of the motor system in language comprehension. Q.J.Exp.Psychol.(Colchester.), 61: 825-850, 2008.

Gallese V and Lakoff G. The Brain's Concepts: The Role of the Sensory-Motor System in Reason and Language. Cognitive Neuropsychology, 22:455-479, 2005. 
Gastaut H. [Electrocorticographic study of the reactivity of rolandic rhythm.]. Rev.Neurol.(Paris), 87: 176-182, 1952.

Goldfield BA. Nouns before verbs in comprehension vs. production: the view from pragmatics. J.Child Lang, 27: 501-520, 2000.

Hari R, Salmelin R, Makela JP, Salenius S, and Helle M. Magnetoencephalographic cortical rhythms. Int.J.Psychophysiol., 26: 51-62, 1997.

Hauk O, Johnsrude I, and Pulvermuller F. Somatotopic representation of action words in human motor and premotor cortex. Neuron, 41: 301-307, 2004.

Hebb DO. The Organization of Behavior. A Neuropsychological Theory. New York: Wiley, 1949.

Kable JW, Kan IP, Wilson A, Thompson-Schill SL, and Chatterjee A. Conceptual representations of action in the lateral temporal cortex. J.Cogn Neurosci., 17: 1855-1870, 2005.

Kable JW, Lease-Spellmeyer J, and Chatterjee A. Neural substrates of action event knowledge. J.Cogn Neurosci., 14: 795-805, 2002.

Kemmerer D, Castillo JG, Talavage T, Patterson S, and Wiley C. Neuroanatomical distribution of five semantic components of verbs: evidence from fMRI. Brain Lang, 107: 16-43, 2008.

Keysers C and Perrett DI. Demystifying social cognition: a Hebbian perspective. Trends Cogn Sci., 8: 501-507, 2004.

Kiefer M, Sim EJ, Herrnberger B, Grothe J, and Hoenig K. The sound of concepts: four markers for a link between auditory and conceptual brain systems. J.Neurosci., 28: 12224-12230, 2008.

Kiefer M, Sim EJ, Liebich S, Hauk O, and Tanaka J. Experience-dependent plasticity of conceptual representations in human sensory-motor areas. J.Cogn Neurosci., 19: 525-542, 2007.

Kilner JM, Neal A, Weiskopf N, Friston KJ, and Frith CD. Evidence of mirror neurons in human inferior frontal gyrus. J.Neurosci., 29: 10153-10159, 2009.

Lahav A, Saltzman E, and Schlaug G. Action representation of sound: audiomotor recognition network while listening to newly acquired actions. J.Neurosci., 27: 308-314, 2007.

Mahon BZ and Caramazza A. A critical look at the embodied cognition hypothesis and a new proposal for grounding conceptual content. J.Physiol Paris, 102: 59-70, 2008.

Martin A, Haxby JV, Lalonde FM, Wiggs CL, and Ungerleider LG. Discrete cortical regions associated with knowledge of color and knowledge of action. Science, 270: 102-105, 1995. 
Martin A, Wiggs CL, Ungerleider LG, and Haxby JV. Neural correlates of category-specific knowledge. Nature, 379: 649-652, 1996.

McNamara A, Buccino G, Menz MM, Glascher J, Wolbers T, Baumgartner A, and Binkofski F. Neural dynamics of learning sound-action associations. PLoS.One., 3: e3845, 2008.

Oldfield RC. The assessment and analysis of handedness: the Edinburgh inventory. Neuropsychologia, 9: 97-113, 1971.

Patterson K, Nestor PJ, and Rogers TT. Where do you know what you know? The representation of semantic knowledge in the human brain. Nat.Rev.Neurosci., 8: 976-987, 2007.

Pfurtscheller G, Neuper C, Andrew C, and Edlinger G. Foot and hand area mu rhythms. Int.J.Psychophysiol., 26: 121-135, 1997.

Pineda JA. Sensorimotor cortex as a critical component of an 'extended' mirror neuron system: Does it solve the development, correspondence, and control problems in mirroring? Behav.Brain Funct., 4: 47, 2008.

Pulvermuller F. Words in the brain's language. Behav.Brain Sci., 22: 253-279, 1999.

Pulvermuller F. Brain mechanisms linking language and action. Nat.Rev.Neurosci., 6: 576-582, 2005.

Pulvermuller F, Shtyrov Y, and Ilmoniemi R. Brain signatures of meaning access in action word recognition. J.Cogn Neurosci., 17: 884-892, 2005.

Revill KP, Aslin RN, Tanenhaus MK, and Bavelier D. Neural correlates of partial lexical activation. Proc.Natl.Acad.Sci.U.S.A, 105: 13111-13115, 2008.

Rizzolatti G, Fadiga L, Gallese V, and Fogassi L. Premotor cortex and the recognition of motor actions. Brain Res.Cogn Brain Res., 3: 131-141, 1996.

Shtyrov Y, Nikulin VV, and Pulvermuller F. Rapid cortical plasticity underlying novel word learning. J.Neurosci., 30: 16864-16867, 2010.

Simmons WK and Barsalou LW. The similarity in topography principle: Reconciling theories of conceptual deficits. Cognitive Neuropsychology, 20 (3/4/5/6), 451-486, 2003.

Tettamanti M, Buccino G, Saccuman MC, Gallese V, Danna M, Scifo P, Fazio F, Rizzolatti G, Cappa SF, and Perani D. Listening to action-related sentences activates fronto-parietal motor circuits. J.Cogn Neurosci., 17: 273-281, 2005. 
Thompson-Schill SL. Neuroimaging studies of semantic memory: inferring "how" from "where". Neuropsychologia, 41: 280-292, 2003.

van EM, van Schie HT, Zwaan RA, and Bekkering H. The functional role of motor activation in language processing: motor cortical oscillations support lexical-semantic retrieval. Neuroimage., 50: 665-677, 2010.

Weisberg J, van TM, and Martin A. A neural system for learning about object function. Cereb.Cortex, 17: 513-521, 2007.

Willems RM, Toni I, Hagoort P, and Casasanto D. Neural dissociations between action verb understanding and motor imagery. J.Cogn Neurosci., 22: 2387-2400, 2010. 


\section{Figures captions}

Figure 1: Examples of videos used in the experiment. Four screen-shots of two videos of hand/arm movements: a) a "zig-zag" movement with a vertically oriented cylinder and b) a "crawling" movement with an horizontally oriented cylinder. c) Four screen-shots of an image video and two more examples of the images used in the experiment.

Figure 2: Topography of $\mu$ oscillations $(8-12 \mathrm{~Hz}$ range) averaged over a time window of 250$1000 \mathrm{msec}$ after stimulus onset while watching videos. Data shows the difference between the movement- and the image-condition for each of the four test sessions (pretest, test 1 , test 2 and test 3 ).

Figure 3: Time-frequency analysis (5-30 Hz domain) performed over two clusters during presentation of videos: A) centro-parietal cluster (CP1, CP3, P3 and Pz) and B) fronto-central cluster (Fz, F3, F4, FC1, FC3, FC2 and FC4).

Data are plotted from $-200 \mathrm{msec}$ to $1000 \mathrm{msec}$ post-video onset for the four test-sessions. Top row: "Movement condition". Middle row: "Image condition". Lower row: "Movement minus Image" contrast. As indicated by the scale, a blue shaded area corresponds to a reduction of the amplitude of oscillations in a given frequency band while a red shaded area corresponds to an enhancement of the amplitude of oscillations.

Figure 3: C) Time-course of $\mu$ oscillations during presentation of videos at both centro-parietal (top row) and fronto-central (lower row) clusters for the four test sessions. Data are plotted from -200msec to $1000 \mathrm{msec}$ relative to video onset. Red curves represent data for the image condition, black curves for the movement condition. For both conditions, each curve represents one electrode.

Figure 4: Time-frequency analysis $(5-30 \mathrm{~Hz}$ domain) performed over two clusters during presentation of verbal stimuli: A) centro-parietal cluster (CP1, CP3, P3 and Pz) and B) fronto-central cluster (Fz, F3, F4, FC1, FC3, FC2 and FC4). Data are plotted from -200 msec to $1000 \mathrm{msec}$ post-stimulus onset and for all test sessions. Top row: Movement condition. Middle row: Image condition. Lower row: "Movement minus Image" contrast. As indicated by the scale, a blue shaded area corresponds to a reduction of the amplitude of oscillations in a given frequency band while a red shaded area corresponds to an enhancement of the amplitude of oscillations.

Figure 4: C) Time-course of $\mu$ oscillations during presentation of verbal stimuli at both centro-parietal (top row) and fronto-central (lower row) clusters for the four test sessions. Data are plotted from $200 \mathrm{msec}$ to $1000 \mathrm{msec}$ relative to video onset. Red curves represent data for the image condition, black curves for the movement condition. For both conditions, each curve represents one electrode. 
Click here to download Suppl. material for online publication only: Fargier et al. Suppl. material.doc Suppl. material for online publication only Click here to download Suppl. material for online publication only: Fargier et al. Suppl. material.doc

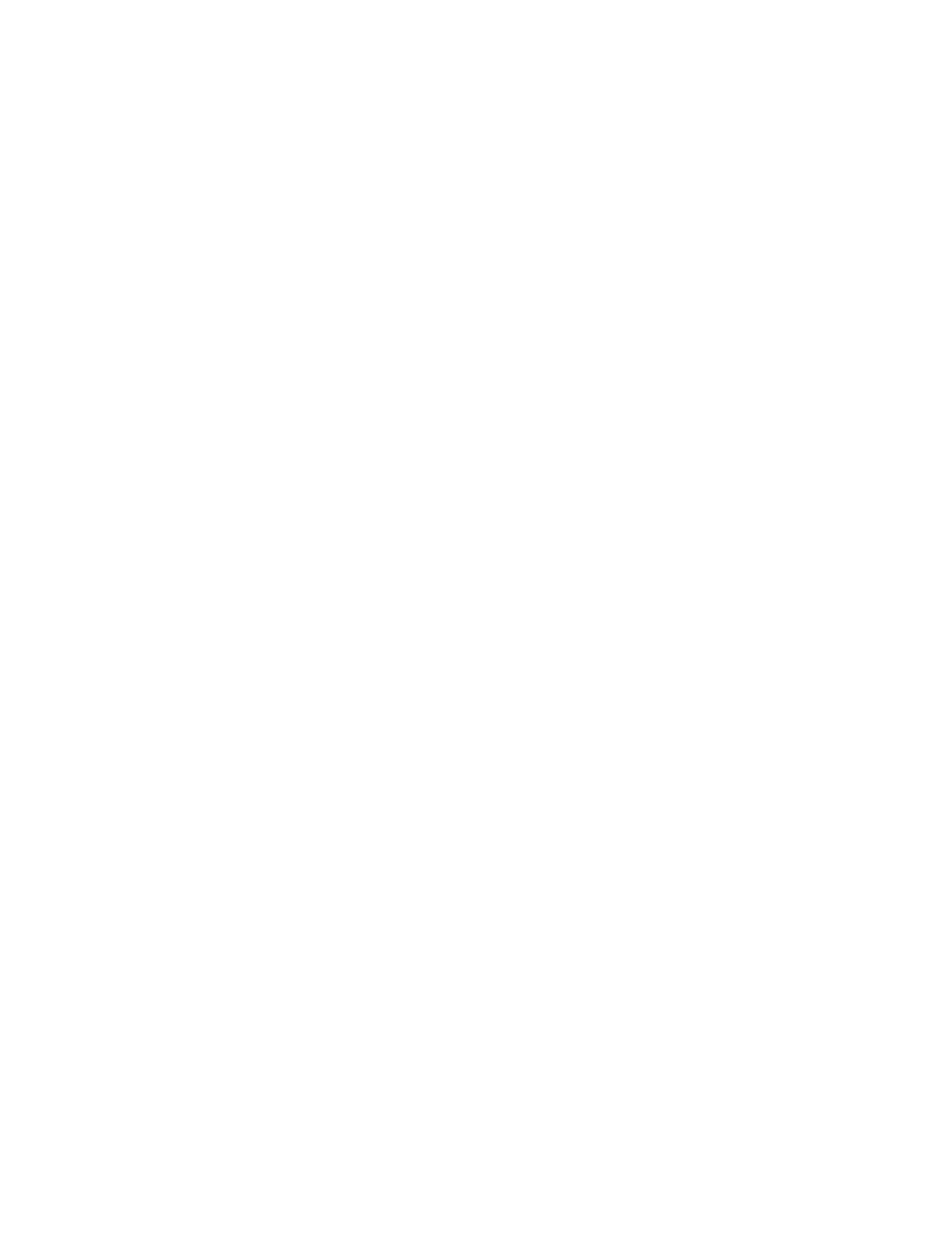


Click here to download high resolution image

a
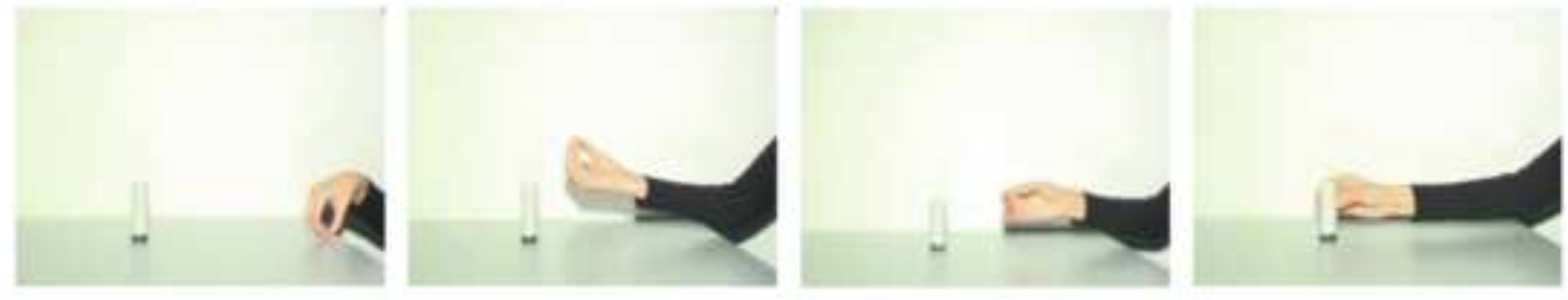

b

C
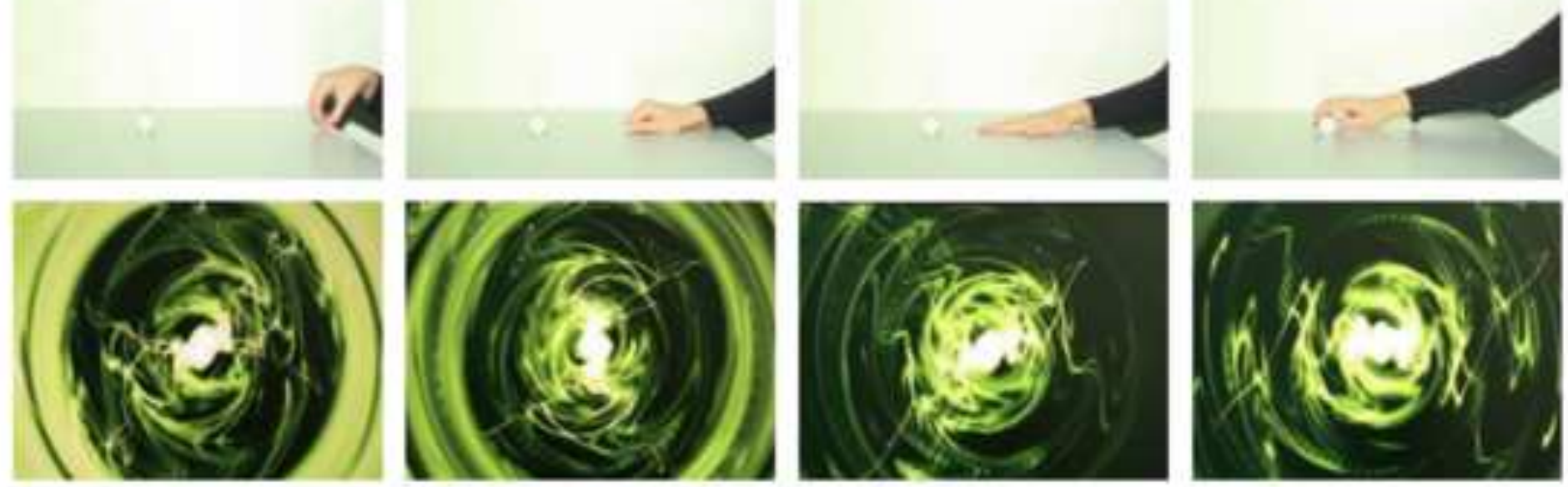

d
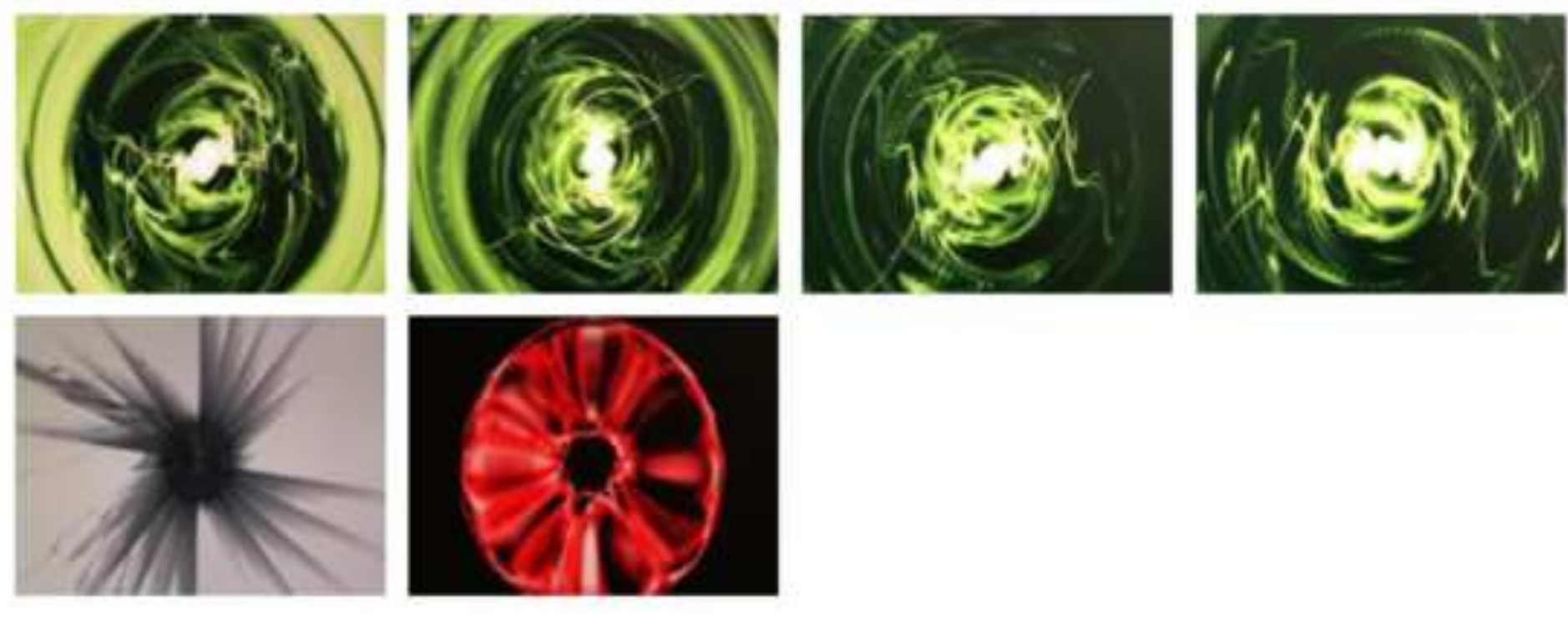


\section{gure 2}

Click here to download high resolution image
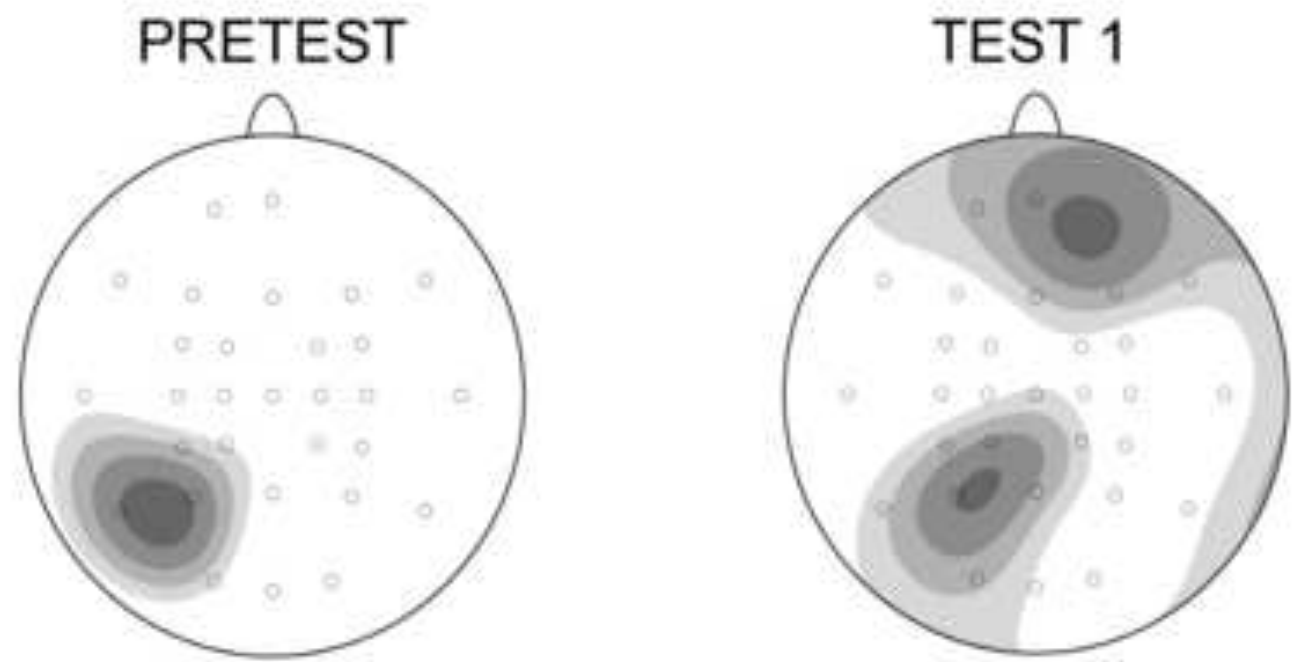

\section{TEST 2}

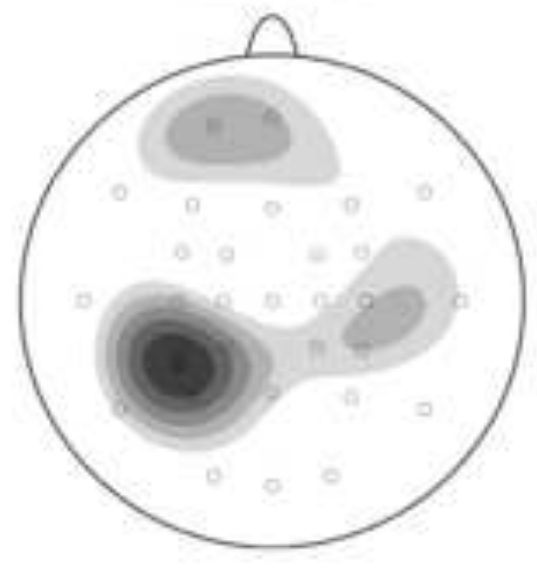

TEST 3

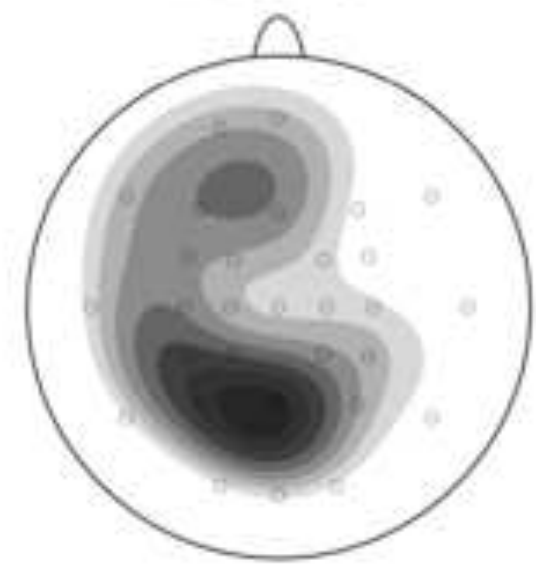

$250 \mathrm{~ms}-1000 \mathrm{~ms}$

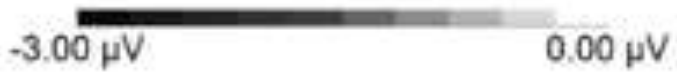


Click here to download high resolution image

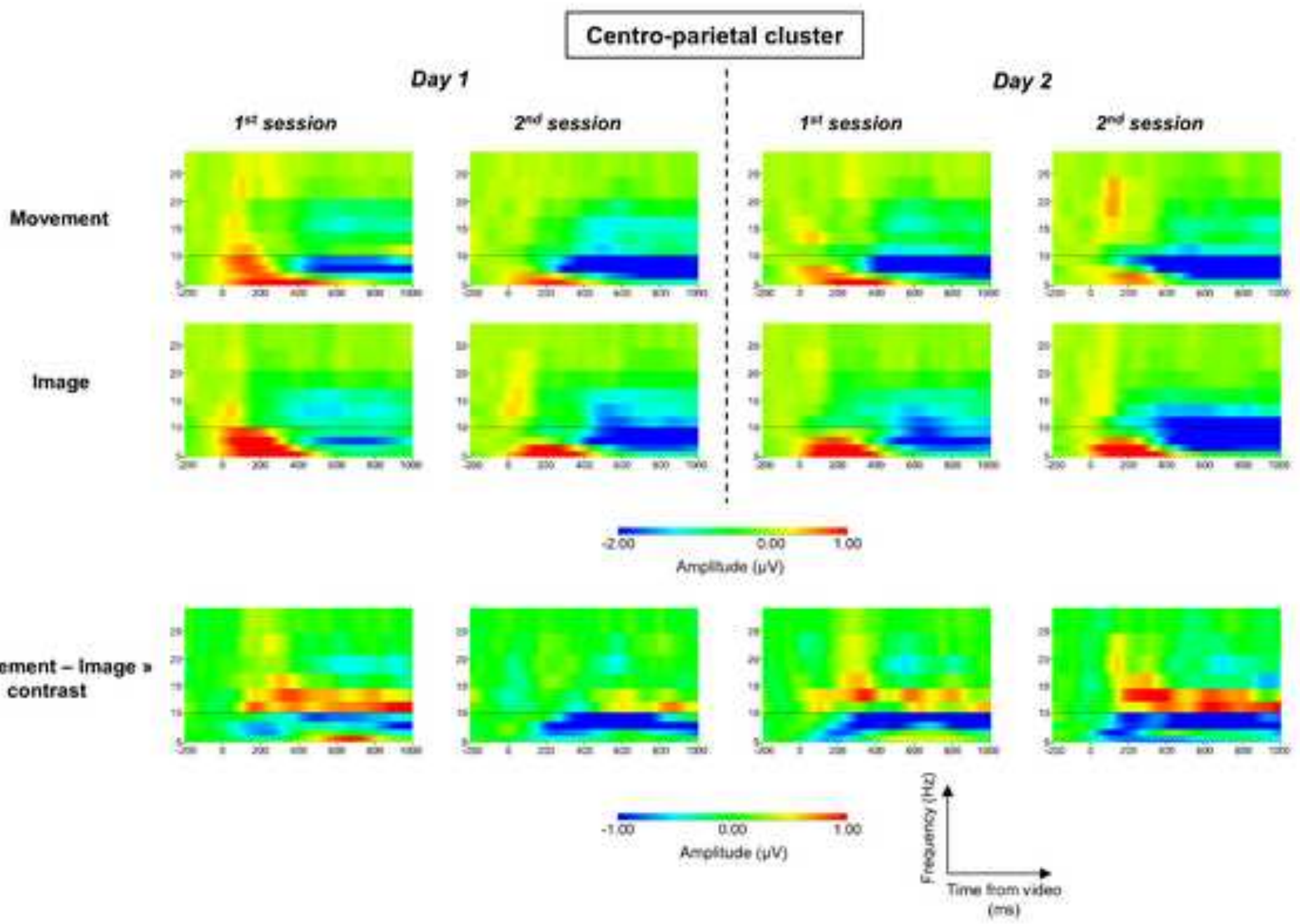


Click here to download high resolution image

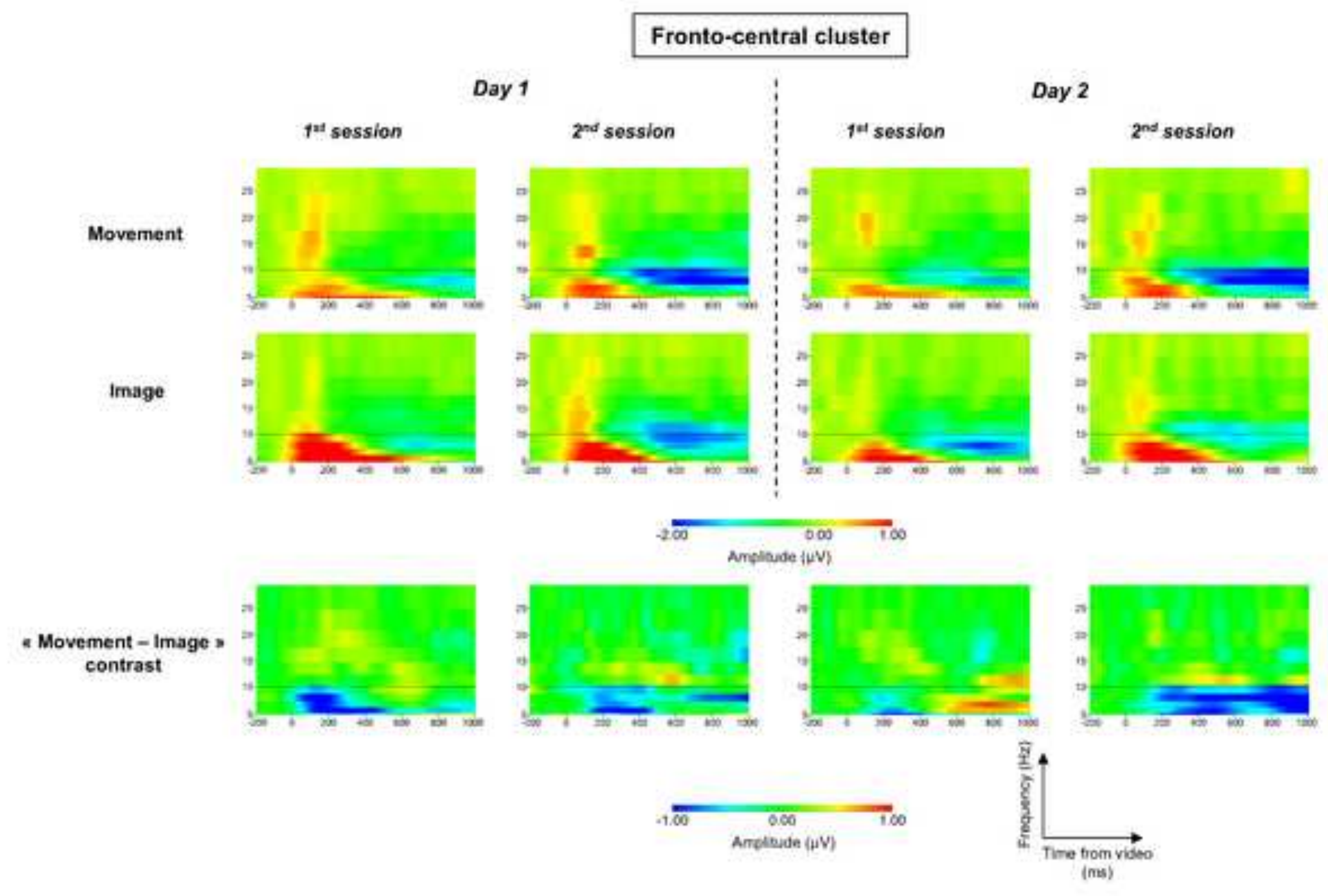


Click here to download high resolution image

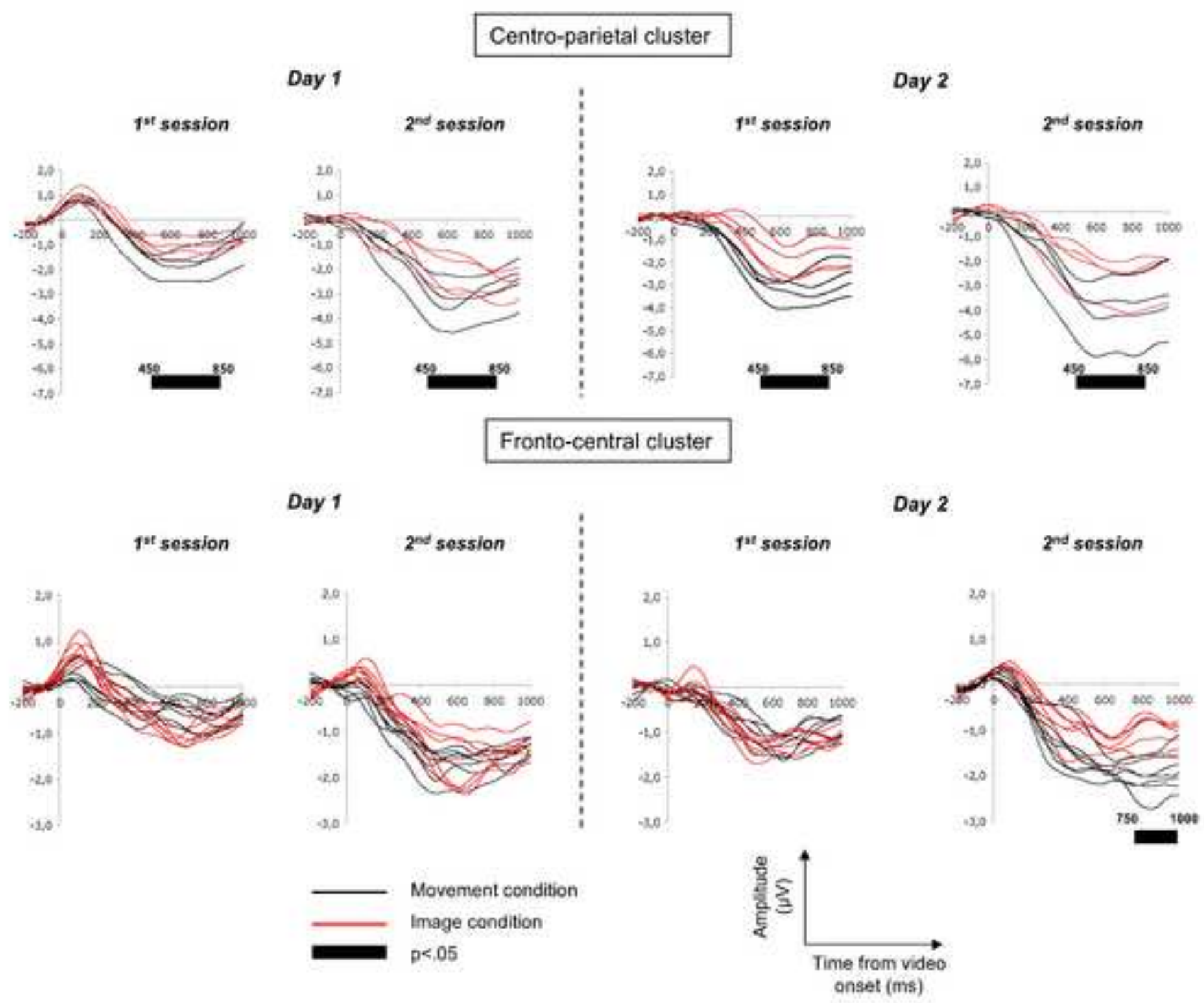


Click here to download high resolution image

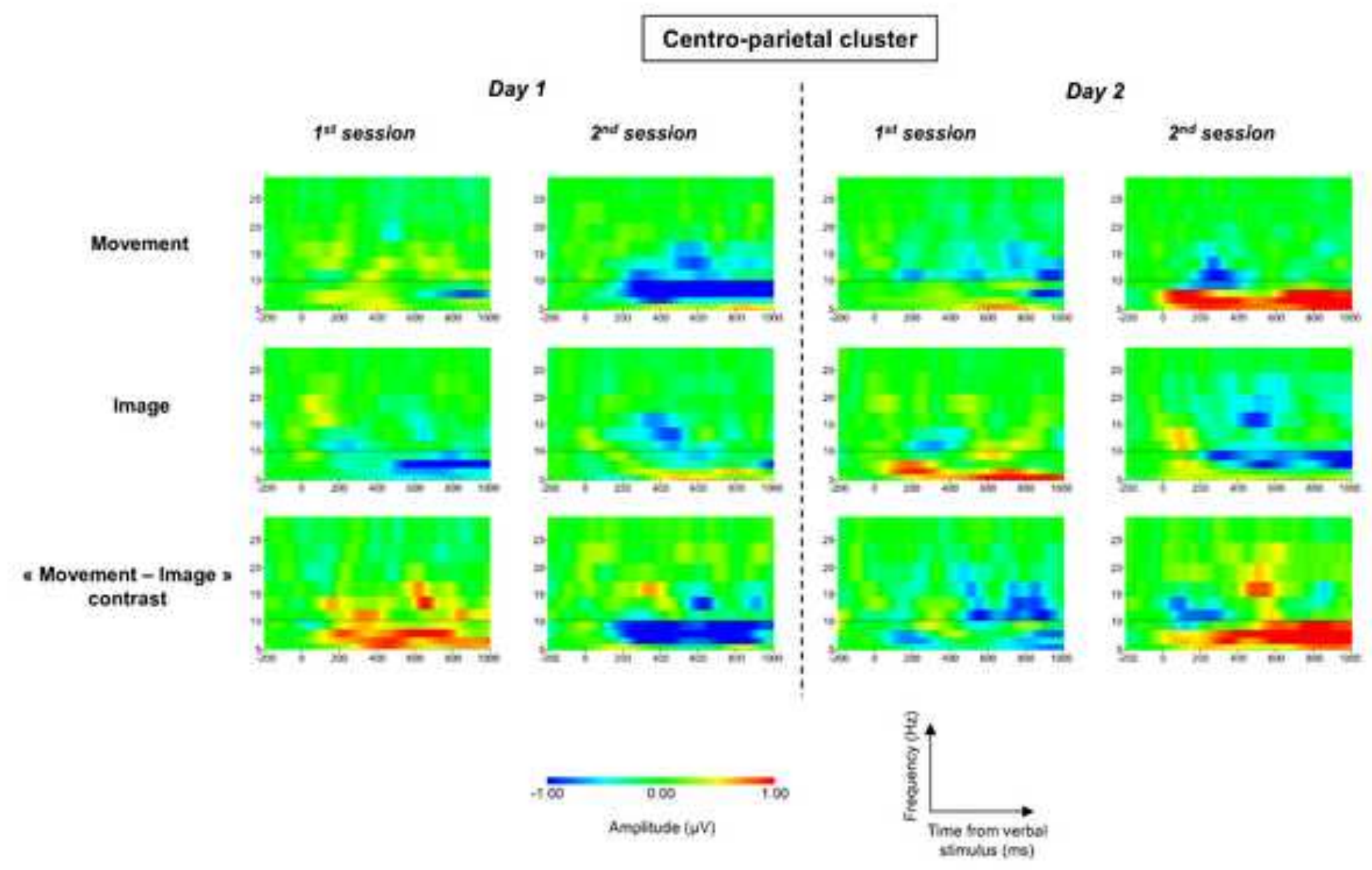


Click here to download high resolution image

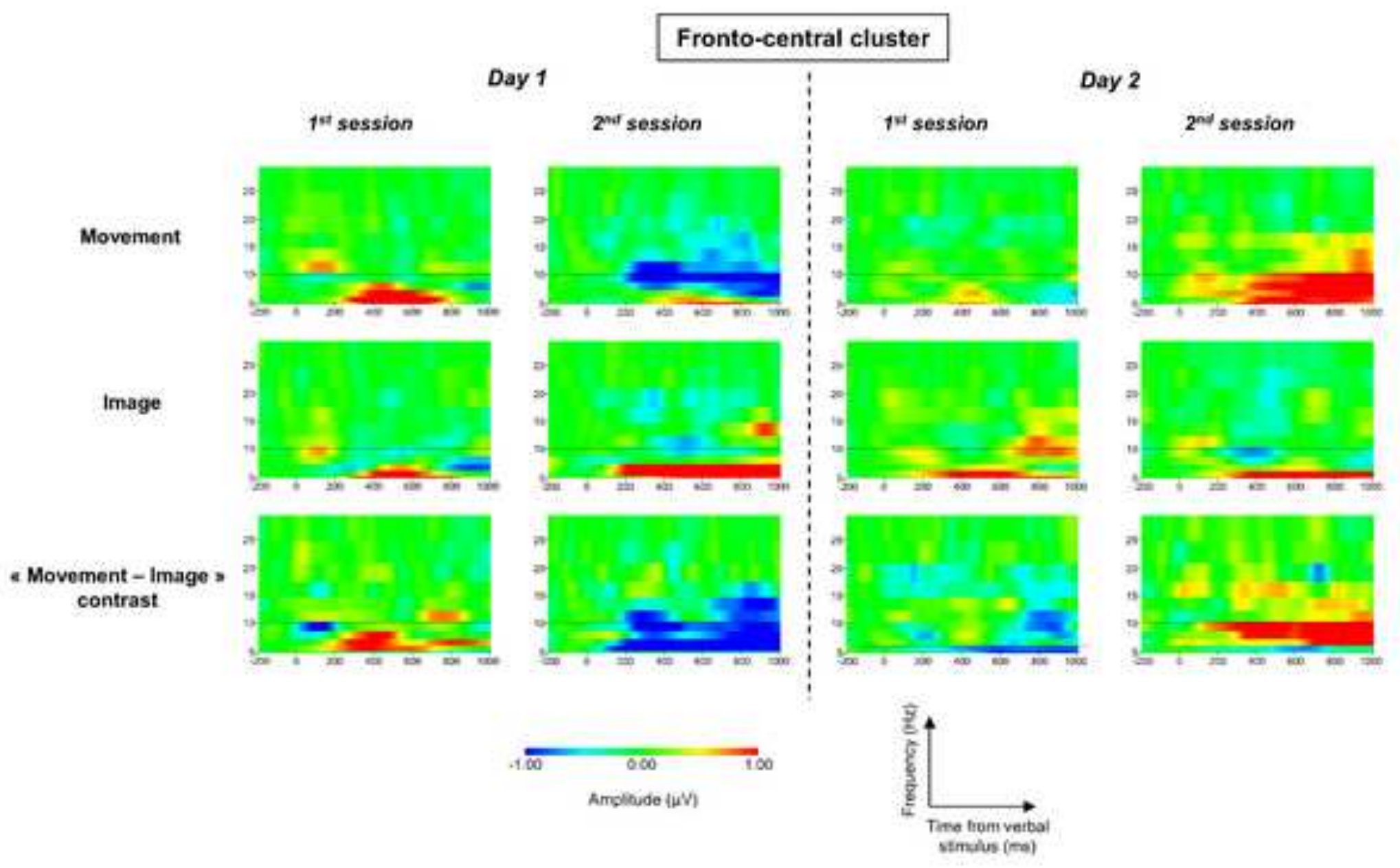


Click here to download high resolution image

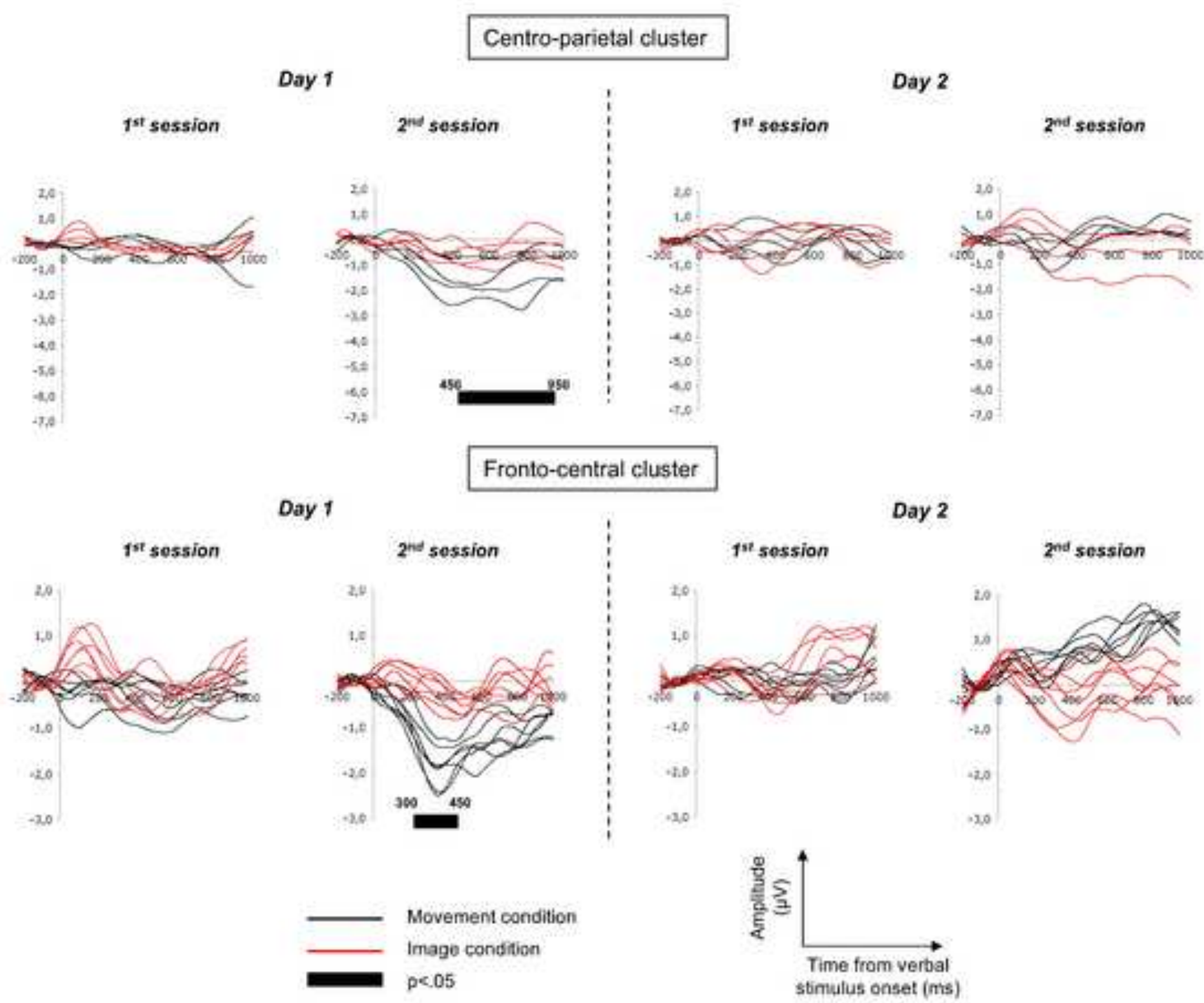

